\title{
A probe into the causes of population loss in ShanDong province
}

\author{
Yong Che, Jing Wang \\ North West Agriculture and Forestry University School of Economics and Management \\ YangLing, China \\ 841325746@qq.com

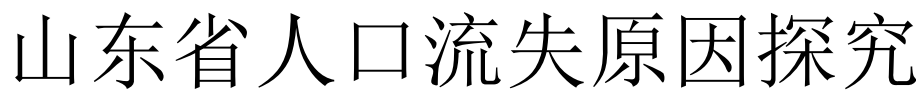 \\ 车永, 王静 \\ 西北农林科技大学经济管理学院 \\ 陕西 712100, 中国 \\ 841325746@qq.com
}

\begin{abstract}
In 2017, there exists a serious population loss phenomenon in Shandong Province. Today, we advocate "a powerful country with talent and resources". Serious population loss leads to the decline of population dividend effect, the aggravation of population aging, and the increase of social security burden, which is not conducive to the sustainable and coordinated development of regional economy. On the basis of screening and sorting out the current situation of population loss and the structure of floating population in Shandong Province, this paper uses SPSS data to analyze the main factors affecting population loss in Shandong Province by comparing 17 influencing factors of population flow in 30 provinces and municipalities based on Todaro model, and draws the population of Shandong Province from the current actual situation in Shandong Province. The root causes of the loss are summarized and some suggestions are put forward.
\end{abstract}

Keywords-Population loss; Demographic dividend; ShanDong Economic; Todaro model; SPSS

摘要一2017 年山东省出现了严重的人口流失现象, 在倡导 “人才资源强国” 的今天，严重的人口流失导致人口红利效 应下降, 人口老龄化加剧, 增加了社会保障负担, 且不利于 区域经济的可持续与协调发展。本文在篮选梳理山东省人口 流失现状、流动人口结构等相关数据的基础上, 基于托达罗 模型通过比较 30 个省市的 17 的人口流动影响因子利用 SPSS 数据分析得出影响山东省人口流失的主要因子并就山东省目 前的实际情况分析出山东省人口流失的基本原因最后总结并 提出针对性的建议。 SPSS

关键词一人口流失, 人口红利, 山东经济, 托达罗模型,

$$
\text { I. 引言 }
$$

山东省作为一个人口经济大省, 2018 年经济总量全 国各省排名第三人口总量排名第二，在 2017 年出现了严 重的人口流失现象, 人口净流失 42.46 万人, 全国各省 人口净流失量排名第一。人口是经济发展的基础, 而山 东省的人口老龄化问题日益严重，已成为全国人口老龄 化最严重的省份。创新是引领发展的第一动力, 而人才 则是支撑发展的第一资源。严重的人口流失一方面会改 变山东省的人口结构, 加剧人口老龄化问题增加社会负
担; 另一方面, 大量劳动力的流失无疑会对山东省的经 济发展造成巨大的冲击。当经济进入快速发展时期, 人 口红利在影响生产领域与消费和储蓄的同时必定会成为 经济增长的有利助推器。依据索罗模型, 经济发展是劳 动力资源的增函数, 总的劳动力下降必然会造成经济发 展的下降。如果人口流失的问题得不到解决, 会进一步 阻碍山东省经济的发展, 甚至影响到山东的整体发展。

\section{II. 人口流失的相关概念与测算方法}

人口流失：“流失” 反映的是有用的东西因为 “流”这个过程而散失或离开的现象; “人口流失” 是 指原有人口由于流动迁移这个过程而减少的现象。人口 流失并不等同于人口减少, 人口减少的原因还有可能是 人口自然负增长造成的。衡量人口流失的程度可以用总 流失人口和净流失人口作为指标, 总流失人口是指迁出 人口总量, 净流失人口是指迁出人口与迁入人口的差 值, 当迁入人口少于迁出人口时, 才会出现人口流失的 现象。本文将人口流失界定为人口净流出。

\section{A. 测算方法以及数据来源}

人口流失的测算方法: 人口净迁移量=人口变动量 (年末人口总数-去年年末人口总数) -人口自然增长 量。（当人口净迁移量为正时表明人口净流入, 为负时 表明人口净流出)

本文数据来源于: 《2010 年第六次人口普查》、 《2000 年第五次人口普查》、《2018 年山东统计年 鉴》、《2017 年山东统计年鉴》《2017 年中国统计年 鉴》和《2018 年中国统计年鉴》等。

\section{B. 山东省人口流失现状分析}

根据《2018 年中国统计年鉴》的数据, 整理后看出 山东作为一个人口大省, 在 2017 年人口净流出 42.46 万 人, 成为人口流失最为严重的省份, 人口流失较为严重 的省份还有河南省和吉林省, 人口流失量分别为 30.16 万人和 16.71 万人, 分别位列人口流失量排名的第二、 三位。相反, 人口净流入量最大的省份为广东省, 人口 
净流入量达到了 67.69 万人, 其次为浙江省和新疆省, 人口净流入量分别为 31.02 万人和 19.13 万人。

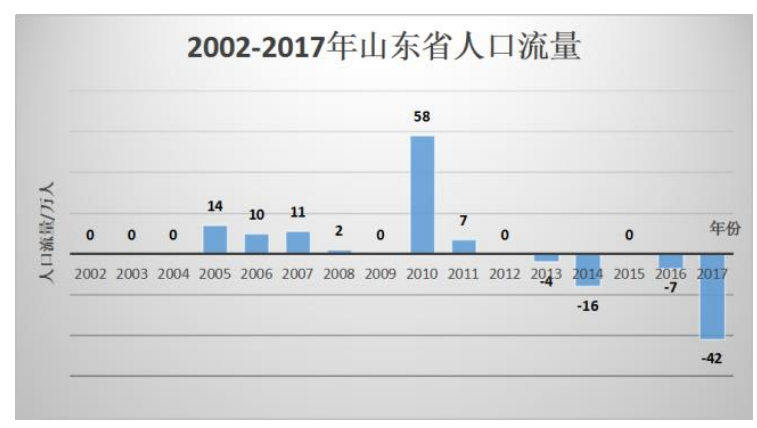

图 1 2002-2017 山东省人口流量

山东人口流失的数量反映了人口流动的总体情况, 人口流失部分的结构分析可以让更直观的表明人口流失 对山东发展带来的影响, 有助于我们探究山东省人口流 失的原因，提出更有针对性的建议对策。本文在分析流 失人口的结构是主要从人口流失部分的年龄结构、流失 人口的省外分布情况及流失人口的受教育程度这三个方 面进行分析

\section{1) 人口流失的年龄结构分析}

通过人口流失的年龄结构测算分析, 可以让我们了 解到人口流失对山东省劳动力资源、少年抚养比、老年 抚养比以及对山东省的年龄结构、人口老龄化程度的影 响, 因此具有十分重要的研究意义。

根据《2018 年山东统计年鉴》山东流动人口中 $85.53 \%$ 是处于 15-64 岁的劳动年龄人口, 其中 $62.49 \%$ 的 流动人口是 15-40 岁的青壮年劳动人口, 说明了流失人 口中的绝大多数都是青壮年劳动力人口, 这部分人口流 失大大的减少了山东省的劳动力数量, 在大多发展中国 家里, 只有劳动力人口的增长效应高于非劳动力人口增 长效应, 才能补偿儿童人口增长以及老年人口增长的物 质消耗, 因此劳动力人口大量流失会使山东省经济面临 严峻的挑战, 劳动力供求必将发生很大变化, 劳动力短缺
将会成为制约经济发展的一大障碍, 由于我国还未完成 工业结构的优化升级, 如果出现劳动力短缺必定会导致 劳动力价格上涨, 这对无论是资本密集型产业还是劳动 密集性产业的发展都是一种阻碍。

\section{2）流失人口的省外分布情况}

2017 年山东省的流出人口主要流向了天津、北京、 江苏、上海这四个省份, 总共占到流动人口总数的 $62.06 \%$, 可以看出这四个省份的经济发展水平较高。 2017 年全国人均 GDP 排名前四的分别是北京、上海、 天津和江苏, 山东在 2017 年人均 GDP 的排名是第八 位, 与这四个地区相比有较大的差距, 从这里我们可以 初步发现经济发展水平是影响人口流动的重要因素。而 像人口净流入量较大的新疆省的经济发展水平并不是十 分突出, 新疆人口流入的原因则主要是我国这几年出台 的一些西部人口保护政策和人才引进政策, 因此在分析 山东省人口流失的原因时我们也会考虑到引进政策等其 他方面的原因作为影响因素。

\section{3) 流失人口的受教育程度}

表 1 反映的是 2014 年山东省流动人口和 2010 年常 住人口受教育程度对比, 从表 1 , 可以看出流出人口的 受教育程度远远大于常住人口的受教育程度。随着经济 教育水平的发展, 这种现象只会愈演愈烈, 人口流失在 很大程度上流失的不仅仅是一般劳动力, 而更意味着一 大批高尖端人才的流失, 这时人口流失对山东省造成的 损失更大, 因为受教育程度的高低往往跟对社会生产力 的贡献是成正比的, 高学历、高素质人才在流失人口中 占比较大, 而这些人才的流失则会从根本上影响山东地 区在产业结构转型中的主动性和竞争。由于这几年的人 才大战, 受各个省份人才政策的影响, 流动人口有很大 一部分高学历人才, 它们不仅影响了一个地区生产力的 发展提高, 也会影响一个地区经济发展的活力。众所周 知, 人才是第一生产力, 高尖端人才对一个地区经济、 文化，消费，产业结构升级等各方面的带动作用是十分 强大的，因此我们应该十分重视山东省的人口流失问题 的解决。

表 12014 山东省流动人口学历分析（数据来源：2014 年山东省统计年鉴）单位：人，\%

\begin{tabular}{cccccccc}
\hline \multirow{2}{*}{ 学历 } & \multicolumn{2}{c}{ 被调查山东省流入人口 } & \multicolumn{2}{c}{ 跨省流入 } & \multicolumn{2}{c}{ 跨省流出 } & 2010 年常住人口 \\
\cline { 2 - 8 } & 流入 & 占比\% & 流入 & 占比 & 学历 & 流入 & 占比 \\
\hline 未上学 & 31 & 0.52 & 14.00 & 1.56 & 未上学 & 31 & 0.52 \\
小学 & 391 & 6.52 & 106.00 & 11.78 & 小学 & 391 & 6.52 \\
初中 & 3132 & 52.19 & 486.00 & 54.00 & 初中 & 3132 & 52.19 \\
高中 & 1450 & 24.16 & 204.00 & 22.67 & 高中 & 1450 & 24.16 \\
大学专科 & 226 & 3.77 & 64.00 & 7.11 & 大学专科 & 226 & 3.77 \\
大学本科 & 756 & 12.60 & 25.00 & 2.78 & 大学本科 & 756 & 12.60 \\
研究生 & 15 & 0.25 & 1.00 & 0.11 & 研究生 & 15 & 0.25 \\
\hline
\end{tabular}

III. 山东省人口流失问题的数学模型及实证分析

托达罗模型: 托达罗模型又称作三部门模型, 是关于 农村劳动力向城市迁移决策和就业概率劳动力流动行为 的模型, 其理论主要认为农业劳动者迁入城市的主要原 因在于预期的城乡收入差距, 且与收入差距成正比此外 还包括就业对劳动力在农业与工业之间人口流动的影 响。托达罗认为在发展中国家失业率较高, 而且人口是 在农村没有剩余劳动力的情况下流动。因此不仅会导致
城市的就业形势紧张失业率增加, 还会导致农村的劳动 力不足以致农村经济的发展所以应该合理的控制农村劳 动力流入城市的数量并促进农村农业的发展和加强农村 的综合开发增加农村就业机会。此模型的缺陷在于只考 虑了迁移成本没有考虑到城市的生活成本以及流动人口 的区域偏好影响。数学表述如下:

$$
M_{\mathrm{t}}=f\left(P_{t} * Y_{u}(t)-Y_{r}(t)\right), \quad \frac{d M}{d f}>0
$$


其中, $P_{\mathrm{t}}$ : 劳动者在城市能够就业的概率, $Y_{\mathrm{u}}(\mathrm{t})$ : 城市的收入水平, $Y_{\mathrm{r}}(\mathrm{t})$ : 农村收入水平, $M_{\mathrm{t}}$ : 劳动者迁移 行为。若 $M_{\mathrm{t}}>0$ 则迁移行为会发生, $M_{\mathrm{t}}<\mathbf{0}$ 不会发生迁 移行为。

若是考虑到迁移成本因素与多期决策行为则

$$
V_{0}=\int_{0}^{\mathrm{n}}\left[P_{t}^{*} Y_{u}(t)-Y_{r}(t)\right] e^{-r t} d t-C_{(0)}
$$

其中, $V_{0}$ : 劳动者净收入按照贴现率 $\mathrm{r}$ 的贴现值, $\mathrm{n}$ : 总决策时间, $C_{(0)}$ : 迁移成本。其中, $V_{0}>0$ 时，农村 的剩余劳动力会迁移到城市, 农村人口减少城市人口增 加, 反之则不会发生人口迁移

拓展后托达罗模型：山东地区的人口流失问题可以 使用托达罗模型模型进行分析。在此将 $Y_{\mathrm{u}}(\mathrm{t})$ 视为人口流 入地区的收入水平, $Y_{\mathrm{r}}(\mathrm{t})$ 看做山东地区的收入水平。在 区域之间的人口迁移与城乡人口迁移有所不同: 第一, 对于不同地区之间人口迁移的劳动者, 无论在山东还是 非山东地区其就业概率都小于 1 。第二，迁移劳动者的 收入水平等于真实收入水平减去消费水平流动人口在山 东地区和流入地区的真实收入水平分别为 $I_{\mathrm{u}}(\mathrm{t})$ 和 $I_{\mathrm{r}}(\mathrm{t})$, 消 费水平为 $E_{\mathrm{u}}(\mathrm{t})$ 和 $E_{\mathrm{r}}(\mathrm{t})$ 于是拓展后的托达罗模型为

$$
V_{(0)}=\int_{0}^{\mathrm{n}}\left\{\left[P_{u}(t) * I_{u}(t)-E_{u}(t)\right]-\left[P_{r}(t) * I_{r}(t)-E_{r}(t)\right]\right\} e^{-r t} d t-C_{(0)}
$$

当 $V_{(0)}>0$ 时, 劳动力会从山东地区流入外地, 反之 则留在山东地区。

通过式(3)我们可以进一步的分析影响山东人口流出 的因素: 1.山东地区和人口流入地区的收入水平与消费 水平的区别 2.山东地区和人口流入地区的就业率的差别 3. 从山东地区迁出的迁移成本 4. 计划的时间长度 $n$ 与贴 现率 $r$

显然, 山东地区的人口流失问题不仅和山东地区本 地有关, 还和人口的流入地有关, 且绝对多数人口是在 国内流动。因此为了明确影响山东人口流失的因素, 需 要在全国范围内来进行对比分析。在拓展的托达罗模型 中可以知道影响人口流动的基本因素有收入水平 就业水
平 迁移成本以及时间价值。这些因素又可以进一步指标 化分为经济发展指标 社会保障水平指标社会生活环境 指标 经济生产结构四大类。这四个大指标可以进一步 分为以下系列的指标。选取指标如下: 因变量: 各个地 区的人口流入量, 自变量: 影响各个地区人口流入量的 因素。自变量指标分为以下:

(1)经济发展指标:根据拓展的托达罗模型选取的影响 指标如下: $E_{1}$ 各省市人均生产总值 (元/人) $E_{2}$ 地区生产 总值 (亿元) $E_{3}$ 各省市消费品零售总额 $E_{4}$ 各省市城乡居 民年终人民币储蓄总额 $E_{5}$ 城镇单位就业人数 $E_{6}$ 城镇单 位就业人员平均工资 (元) $E_{7}$ 各省市净出口总额 $E_{8}$ 全社 会固定资产投资总额。其实 $E_{1} E_{2}$ 反映了各地区经济的发 展水平 $E_{3}$ 反映了该地区的消费水平与够买能力 $E_{4}$ 反映 了当地居民可支配收入与消费支出之间的差额, 差额越 多说明该地居民的净收入越多 $E_{5} E_{6}$ 反映了一个地区的就 业率与就业薪酬, 是吸引劳动力流入的重要因素 $E_{7}$ 反映 了地区经济的开放程度。

(2)社会保障水平指标: 社会保障是对劳动者的一种 “强心针” 更高的社会保障水平无疑会吸引更多的劳动 力流入: $E_{0}$ 城镇职工参与养老保险人数 $E_{10}$ 城镇医疗保 险参加人数 $E_{11}$ 参加失业保险人数。

(3)社会生活环境指标; 居住地区的生活环境需要满 足居民的教育医疗消费娱乐等需要。采取以下指标来衡 量: $E_{12}$ 普通高等学校数量 $E_{13}$ 社区服务机构数量 $E_{14}$ 绿 化面积。

(4)经济生产结构指标: 生产结构的不同决定了不同 的劳动力需求结构, 因此对于人口流动有重要的影响 经 济生产结构主要可以看三个产业占比; $E_{15}$ 第一产业占比 $E_{16}$ 第二产业占比 $E_{17}$ 第三产业占比。

下面我们将用 SPSS20 对因变量人口流入量和选取 的 17 个自变量之间做相关分析。由于选取的变量的连续 性属性, 采用 Person 相关系数做检验, 标准为置信度为 0.01 和 0.05 的双侧相关性。

表 22018 年 30 个省市人口流入量与 17 个指标因子相关性分析结果

\begin{tabular}{cccc}
\hline 因子指标 & Person 相关性 & 显著性 (双侧) & $\mathbf{N}$ \\
\hline$E_{1}$ 各省市人均生产总值 (元/人) & $0.601^{* *}$ & 0.01 & 30 \\
$E_{2}$ 地区生产总值 (亿元) & $0.723^{* *}$ & 0 & 30 \\
$E_{3}$ 各省市消费品零售总额 (亿元) & $0.892^{* *}$ & 0 & 30 \\
$E_{4}$ 各省市城乡居民年终人民币储蓄总额 $($ 亿元) & $0.813^{* *}$ & 0 & 30 \\
$E_{5}$ 城镇单位就业人员 (万人) & $0.605^{* *}$ & 0.076 & 30 \\
$E_{6}$ 城镇单位就业人员平均工资 (元) & $0.734^{* *}$ & 0.005 & 30 \\
$E_{7}$ 各省市净出口总额 (亿元) & $0.926^{*}$ & 0.029 & 30 \\
$E_{8}$ 全社会固定资产投资总额 (亿元) & 0.278 & 0.015 & 30 \\
$E_{9}$ 城镇人口参与养老保险人数 (万年) & $0.653^{* *}$ & 0 & 30 \\
$E_{10}$ 城镇医疗保险参加人数 (万人) & $0.759^{* *}$ & 0 & 30 \\
$E_{11}$ 参加失业保险人数 (万人) & $0.810^{* *}$ & 0 & 30 \\
$E_{12}$ 高等学校数量 (个) & $0.395^{*}$ & 0.030 & 30 \\
$E_{13}$ 社区服务机构数量 (个) & $0.575^{*}$ & 0 & 30 \\
$E_{14}$ 绿化面积 (公顷) & -0.149 & 0.350 & 30 \\
$E_{15}$ 第一产业占比 (\%) & $-0.523^{* *}$ & 0.013 & 30 \\
$E_{16}$ 第二产业占比 $(\%)$ & -0.059 & 0.625 & 30 \\
$E_{17}$ 第三产业占比 $(\%)$ & $0.421^{*}$ & 0.010 & 30 \\
\hline
\end{tabular}

*在置信度 (双侧) 为 0.05 时相关性显著, **在置信度 (双侧) 为 0.01 时相关性显著 


\section{IV. 山东省人口流失原因总结}

\section{A. 落后的产业结构是山东省经济发展疲软以及人口大 量流失的根本原因}

在市场经济主导下的竞争形态中, 既作为劳动力供给 者又作为消费者的理性人会根据自身的效用和发展预期 选择适合自身的居住地。影响山东省人口流失的原因是 多方面的, 但是其中最主要的原因是落后的产业结构。 逐渐不能适应改革开放后新兴产业迅速兴起的信息社会 的发展方式, 使山东省的经济逐渐失去了活力, 无法为 在教育迅速发展大环境下社会培养的大量高素质人才提 供更好的生存空间和更加广阔的发展前景。山东省的主 要产业支柱一一重工业, 作为一个夕阳产业, 已经没有 能力创造更多的经济效益与就业岗位。相比之下第三产 业的发展水平是衡量一个地区发展水平和程度的重要标 志, 大力推进和促进第三产业的发展是保证我国经济平 稳健康持续发展强而有力的保证, 但是山东省在第三产 业方面发展较为滞后, 这在很大程度上制约着山东经济 的发展以及劳动力需求结构的改善。形成一个 “产业结 构不合理一经济发展水平下降一人口流失加剧一阻碍经 济发展”的恶性循环。（表 2)

\section{B. 未处理好政府与市场之间的关系}

改革开放四十年以来我国经济取得重大发展, 山东 省的经济也有了巨大的提高。改革开放的过程是实现经 济经济由政府主导逐步转变为市场主导。让 “看不见的 手与看的见得手” 协调配合更好的发挥市场机制的作用 从而实现经济的快速持续均衡健康发展。山东省在政府 转型的路上并不是一帆风顺, 2008 年全球经济爆发以 来, 作为经济总量与人口基数庞大的省份, 山东省经济 下行压力持续加大。一方面, 过去庞大的经济规模带动 经济增速的局面很难再现; 另外经济危机过后, 政府宏 观政策失灵, 扩张性财政政策同扩张性货币政策并存, 拉动经济增长与刺激需求扩张的初衷在政策效果上发生 偏差出现了重工业产能过剩大量产品滞销与工人失业。 同时省内国企民企活跃于银行借贷与私募融资中。省内 经济开始脱实向虚的趋势企业金融杜杆率持续扩大。实 体经济发展不好大量资金从实体经济流入虚拟经济导致 经济失衡发展。

\section{C. 人才政策的失利, 是导致山东人才大量外流的重要 因素}

在愈演愈烈的人才大战中，山东省的人才政策与其 他地区相比是比较欠缺的, 比如经济发展较好的浙江 省、江苏省和广东省等这些城市都更加注重对人才的引 进, 山东省本身在经济发展水平、产业结构和经济发展 的活力方面本身就逊色于这些省份，在注重人才、吸引 人才方面又不如其他省份下，这便使大量的人才被其他 地区吸引过去而造成人才流失的。因此, 相对不完善的 人才政策也是导致山东省人口流失的一个重要原因。

\section{V. 对策建议}

经过上面的分析调查, 我们大致了解了山东省人口 流失的主要原因, 面对我们上面所找出的原因, 有针对 性的提出一些合理化的建议。
A. 优化产业结构, 促进新兴产业的发展, 为经济发展 创造新的活力

1) 加大高新技术产业的发展力度, 加快产业转型。

按照新结构经济学理论框架, 山东地区在某些生产 要素方面是拥有比较优势的。省内人口基数庞大, 拥有 丰富的高新技术创新型人才, 并且山东经济体量巨大, 创业投资资本充裕, 产业转型升级之际, 倾向发展高新 技术产业具有极大前景。但发展高新技术产业中市场参 与者承担更大的风险, 缺乏政府的产业扶持与指导, 省 域内众多传统行业的企业不愿参与进来。政府应该给予 相应的政策支持, 为其完善软、硬件基础设施, 针对创 新型企业施予外部鼓励和优惠税率, 引导其合作联动、 共御风险, 实现传统行业转型升级, 过渡发展为具有竞 争优势的高新技术产业, 从而为山东经济的发展注入新 的活力, 吸引更多的高素质人才, 在供给侧改革背景下 调整产业结构无疑是刺激区域经济发展的主要动力。

2) 健全升级现代服务体系, 使服务业在一定程度上 带动整个地区人口的流入。

现代服务体系的良性运营是经济持续增长的必要条 件, 山东省在经济发展 “新常态” 阶段, 其相对滞后的 服务业增大省域经济的下行压力, 产业结构转型优化的 必然路径之一就是要健全升级现代服务体系。新结构经 济学强调对创新产业扶持需因势利导, 山东省域服务业 已基本健全, 但仍属落后。地方政府需结合本地发展特 点, 在遵循市场意志的前提下, 适当为部分企业指明服 务业转型升级的前景, 配合企业生产经营。政府应有所 作为, 实践 “有为政府” 的新结构经济学理念。

3) 精细化制造业, 建设具有优势的高端制造业, 创 造更多的就业机会。

要素禀赋结构的提升速度需与产业结构优化升级速 度相匹配, 才能将经济体的潜在比较优势转化为现实比 较优势。政府宜回笼创新型人才, 加快青年创新睬化机 制, 对传统制造业企业施以导向型产业政策、针对创新 型企业施予适当外部性鼓励、协助市场主体积极开拓智 慧产业，建设具有优势的高端制造业。

\section{B. 协调好政府与市场的关系，充分发挥市场的作用}

充分发挥市场的主导作用和政府的主体作用, 提高 资源配置的效率, 促进经济合理健康发展, 让政府与市 场成为推动经济发展的双翼从而减少与其他省份存在的 差距, 减少人口外流。

\section{C. 加大人才政策的投入力度}

各地政府应该加大对人才重视程度, 加大人才政策 的投入力度, 对前来应聘、就业的人才创造最大的便捷 和提供一些福利津贴, 如生活津贴、就业津贴以及购房 津贴等。比起从小培养人才, 这种吸引人才的方式更加 简单、实用、有效。对于人才投资的 “收益率” 非常可 观, 因为他们能为该地区带来的较高经济效益与生产效 率。因此要以更加积极更加开放更加有效的人才政策, 聚天下英才而用之。

\section{$D$. 大力推动高等教育, 提高人才培养质量}

本科教育是高等教育的基础,为社会直接提供了大量 高素质的专业人才。研究生或博士教育的发展, 是学校 提高教学水平和科研能力的关键, 既关系到教师水平与学 
术水平,又关系到高水平的科技成果的转化; 同时也可以 为区域经济的发展培养大量的创新型人才，为经济发展 注入新的活力。

\section{E. 加大对环境保护的投入力度}

发展新能源产业, 加强对企业排放的监督力度, 加 强生态环境建设，走可持续发展的道路。

\section{致谢}

感谢西北农林科技大学经济管理学院王静教授的指导 和支持，本研究由国家自然科学基金农户生产联结 (PPL) 机制及其关联性信用风险演化机理研究资助 (71873101)。

\section{参考文献}

[1] 王安孜. “从鲁苏产业结构对比探寻我省转方式调结构的路径.”山 东经济战略研究,2015(04):23-27.

[2] 王洪娜. “山东省人口迁移流动与区域经济发展研究” 吉林大 学,2015.
[3] 马晓君. “山东省人口年龄结构变动对经济发展的影响” 中央民族 大学, 2012 .

[4] Lewis W A. "Economic Development with Unlimited Supplies of Labour" The Manchester School, 1954, 22

[5]戚伟,刘盛和,金风君. “东北三省人口流失的测算及演化格局研究” 地理科学, 2017,37(12):1795-1804

[6] 杨风. “山东人口迁移流动状况与影响因素” 北京工业大学学报(社 会科学版),2014,14(03):14-20

[7] 尚慧,田娟. “山东产业结构的实证分析一一与广东比较” 现代商贸 工业,2008(10):97-99.

[8] 王森彪,阮陆宁、“山东高等教育发展问题刍议一一基于山东、江 苏、广东三省实证比较” 山东教育学院学报,2008(02):1-3+16.

[9] 高震. “新常态背景下山东产业结构转型升级的研究一一基于新结 构经济学视角分析” 中国集体经济,2019(06):31-32.

[10] 周丽萍,王婷. “基于政府宏观调控下的浙江流入人口变动研究” 统 计科学与实践,2018(05):4-

[11] 郭亮. “流动人口对地区经济社会发展的影响” 中国统 计,2013,(7):16-18.

[12] 朱琳,郑爱文. “流动人口的社会效应及其对经济发展的影响” 商业 时代,2014,(24):42-44.

[13] DongdongZhu,XianhuaWu,PeipeiXue. "Study on the Changes of Industrial Structure in Sichuan Province before and after the ‘512Wenchuan Earthquake',” vol.9. issue 1, 2019,pp.11-19 